\title{
AN ACCEPTABILITY TRIAL OF ETISUL LIQUID FORMULA
}

by S. G. BRowNE, M.D., F.R.C.S., M.R.C.P., D.T.M.

(Leprosy Service Research Unit, Uzuakoli, E. Nigeria)

\section{Introduction}

Favourable reports recently published by DAVY and HogerzeIL (1959), Davey (1959), Lechat (1959 and 1960), Ross et. al. (1960) on the use of Ditophal in the treatment of leprosy have referred to the persistent objectionable odour of the active principle, ethyl mercaptan. Ditophal is Etisul of $\mathrm{ICI}$, which is diethyl dithiolisophthalaté. Messrs. Imperial Chemical Industries, Pharmaceuticals, Ltd. made early attempts to mask this odour by incorporating various perfumes into the original preparation. The resulting cream as used in the trials quoted above was acceptable to most patients. The manufacturers have made further experiments directed towards producing a bulk liquid preparation, which besides being less costly to produce and pack than a cream which is supplied in individual dose tubes of $5 \mathrm{~g}$., would also have certain practical advantages. A liquid preparation was found very acceptable in a trial, applied twice weekly for 3 months to 17 patients at Uzuakoli Leprosarium. An improved product has since been prepared. This is "Etisul Formulation F-565" which is the subject of this report.

\section{The Trial}

For this trial 14 intelligent adult patients, already under treatment with standard doses of Dapsone or Thiambutosine (which is the diphenyl thiourea, Ciba-1906) were invited to co-operate in this acceptability trial of the Etisul liquid preparation. Of the 14 patients 3 already had experience of the standard Etisul cream and with the earlier Etisul liquid preparation: 3 others had previously used the cream only. The dose was $5 \mathrm{ml}$. which could be measured conveniently from the multidose pack into a cylindrical container supplied to each patient, this container having been scored to show the $5 \mathrm{ml}$. level. During the trial there was no absenteeism and all the patients spontaneously continued the treatment for the whole period. There was one exception in a patient who had to cease treatment because of severe recurrence of lepra reaction.

On three occasions the patients were questioned individually and privately (1) after the first four applications twice-weekly; (2) after 3 months; (3) after the end of the trial period of 6 months. The responses were as follows. The 4 patients who had used the Etisul cream previously were unanimous that the Etisul Liquid (Formulation F-565) was much superior to the cream from their point of view. They found that it rubbed in more easily, and disappeared more 
rapidly from the skin. They volunteered the view that the rubbing required a less vigorous effort for a shorter period of time than was necessary with the cream. The mercaptan odour emanating from the skin seemed to be less persistent than was the case with the cream, and it disappeared more completely after a warm bath with scented soap, taken 2 hours after inunction. It seems likely that when the cream was used, a proportion of the active principle was adsorbed on to the surface of the particles of inert and unabsorbable excipient (magnesium stearate) used in the preparation. Since a higher proportion of the active product is probably absorbed percutaneously in the case of the liquid preparation, the therapeutic effect should be greater.

As for persistence of the mercaptan odour in the breath, no difference between the cream and the liquid was noted by those who had experience of both. After 3 months of treatment, all but 2 of the patients found the smell of the liquid quite acceptable, even though several of the new patients had begun the trial with some prejudice against the drug derived from hearsay. By the end of the trial, all the patients were quite enthusiastically in favour.

Our conclusion was that Etisul Liquid Preparation (Formulation F-565 ICI) is a very satisfactory preparation of diethyl dithiolisophthalate for percutaneous administration. It proved acceptable to all 13 patients who used it in $5 \mathrm{ml}$. doses twice weekly for 6 months.

\section{Acknowledgements}

Our thanks are due to Messrs. Imperial Chemical Industries (Pharmaceuticals) Ltd. for a generous supply of Etisul Liquid, and especially to Dr. J. Michael Mungavin for his help and advice.

We thank Dr. S. E. Onwu, M.V.o., O.B.E., Chief Medical Officer, Director of Medical Services, and Perm. Sec. to the Ministry of Health, Eastern Region, Nigeria, for permission to publish.

\section{References}

Davey, T. F. and Hogerzeil, L. M., Leprosy Review, 30, 61 (1959).

DAVEY, T. F., Leprosy Review, 30, 141 (1959).

LeCHAT, M. F., Ann. Soc. belge. Med. trop., 39, 865 (1959).

LeChat, M. F., Leprosy Review, 31, 265 (1960).

Ross, C. M., Telfer, J. F., and Hilton, D. D., Leprosy Review, 31, 260 (1960). 